trị IVIg là 2,3 $\pm 0,923$ là cao hơn có ý nghĩa so với ở nhóm không điều trị IVIg $1,78 \pm 0,441$, điều này tương ứng với mức độ nặng và tiên lượng tử vong của nhóm bệnh nhân điều trị IVIg là cao hơn so với nhóm không điều trị IVIg.

Mặc dù vậy, sự khác biệt về thời gian nằm viện trung bình của hai nhóm là không có ý nghĩa thống kê.

Về đáp ứng điều trị, tỉ lệ tử vong ở nhóm điều trị IVIg là $0 \%$ so với nhóm không điều trị IVIg là $10 \%$. Tuy nhiên, con số này ít có ý nghĩa thông kê do số lượng bệnh nhân nghiên cứu còn ít, cần có các nghiên cứu lớn hơn để khẳng định có hay không về lợi ích của IVIg về tỉ lệ tử vong ở bệnh nhân TEN.

\section{KẾT LUÂNN}

Globulin miễn dịch truyền tĩnh mạch là một trong số phương pháp điêu trị toàn thẩn được áp dụng rộng rãi trên toàn thế giới. Tuy nhiên, tại Việt Nam do giá thành cao và không sẵn có, hiện tại chưa có nhiều bệnh nhân tiếp cận với phương pháp điều trị này. Trong nghiên cứu của chúng tôi, IVIg được sử dụng với các bệnh nhân có tiên lượng kém hơn, nhưng mang lại hiệu quả về thời gian điều trị nội trú là không khác biệt so với bệnh nhân có tiên lượng tốt hơn mà khổng được điều trị IVIg; thậm chí tỉ lệ tử vong của nhóm bệnh nhân này là $0 \%$ thấp hơn so với $10 \%$ ở nhóm bệnh nhân không điều trị IVIg. Tuy nhiên, kết quả này ít có ý nghĩa thống kê do cõ mẫu nhỏ. Cần có những nghiên cứu lớn hơn cũng như lâu hơn để khẳng định tính hiệu quả của IVIg trong điều trị TEN.

\section{TÀI LIÊU THAM KHẢO}

1. Harr T, French LE. Toxic epidermal necrolysis and Stevens-Johnson syndrome. Orphanet J Rare Dis. 2010

2. Dịu PTHB. Đăc điểm lâm sàng, mô bệnh học của một số thể dị ứng thuốc có bọng nước tại khoa Dị ứng - Miễn dịch lẩm sàng, bệnh viện Bạch mai (2004-2005).

3. Fritsch PO, Sidoroff A. Drug-Induced StevensJohnson Syndrome/Toxic Epidermal Necrolysis. Am J Clin Dermatol. 2000;1(6):349-360.

4. Roujeau J-C, Bastuji-Garin $\mathbf{S}$. Systematic review of treatments for Stevens-Johnson syndrome and toxic epidermal necrolysis using the SCORTEN score as a tool for evaluating mortality. Ther Adv Drug Saf. 2011;2(3):87-94.

5. Lương Đức Dũng, Nguyến Văn Đoàn (2015), Nghiên cứu đặc điểm lâm șàng, cận lâm sàng, mô bệnh học và hóa mô miển dịch của hội chứng Stevens-Johnson và Lyell do di ứng thuốc.

6. Phùng Thị Phương Tú, Nguyễn Văn Đoàn, Áp dụng thang điểm SCORTEN trong tiên lượng bệnh nhân hội chứng Stvevens - Johnson, Lyell do dị ứng thuốc. Tạp chí Nghiên cứu Y học, 2013. 81(5).

7. Bayaki Saka, F.B.-T., Felix A. Atadokpe 'de', Le' on Kobangue, Pascal Antoine Niamba, Hugues Ade 'gbidi, Hubert G. Yedomon, Adama Traore, and Vincent P. Pitche Stevens-Johnson syndrome and toxic epidermal necrolysis in sub-Saharan Africa: a multicentric study in four countries. International Journal of Dermatology 2013.

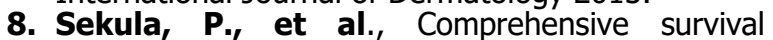
analysis of a cohort of patients with StevensJohnson syndrome and toxic epidermal necrolysis. J Invest Dermatol, 2013.

\title{
ĐẶC ĐIỂM VÔI HÓA ĐộNG MACH CHỦ BỤNG TRÊN HÌNH ẢNH CẮT LỚP VI TÍNH Ở BẾNH NHÂN BỆNH THÂ̂N MẠN TÍNH GIAI ĐOẠN CUỐI
}

\author{
Vũ Thành Đô**, Phạm Quốc Toản*, Phùng Anh Tuấn*
}

\section{TÓM TẮT}

Mục tiêu: Khảo sát đặc điểm vôi hóa động mạch chủ bụng bằng chụp cắt lớp vi tính (CLVT) khổng tương phản ở bệnh nhân bệnh thận mạn tính (BN BTM) giai đoạn cuối. Phướng pháp nghiên cứu: Nghiên cứu trển 89 BN BTM giai đoạn cuối có chỉ định ghép thận tại Bệnh viện Quân y 103. Nhóm chứng gồm 20 BN không có BTM. Đánh giá vôi hóa động mạch chủ bụng trên hình ảnh CLVT không tương phản

\footnotetext{
* Bệnh viện Quân y 103.

** Hoc viến Quân y.

Chịu trách nhiệm chính: Vũ Thành Đô

Email: dr.thanhdovu2318@gmail.com

Ngày nhận bài: 13.9.2021

Ngày phản biên khoa học: 3.11.2021

Ngày duyệt băi: 15.11.2021
}

bằng chỉ số vôi hóa động mach chủ bung $\mathrm{ACI}$ (Abdominal Calcification Index). Kết quả: Nghiên cứu 89 bệnh nhân, gồm 68 nam và 21 nữ với tuổi trung bình median: 36,0 (Min-max: 18-66 tuổi). Vôi hóa động mạch chủ bung được quan sát thây ở 67 bệnh nhân $(75,3 \%)$, điểm ACI trung bình là 8,59 $\pm 10,92$ (\%). Tỷ lệ vôi hóa động mạch chủ bụng khác nhau có ý nghĩa thống kê giữa các nhóm tuổi. Có 3 bệnh nhân trẻ tuổi (Dưới 30) cũng đã xuất hiện vôi hóa động mạch chủ bụng; tỷ lệ này ở nhóm lớn tuổi (Trên 50 ) là $100 \%$. $83,3 \%$ bệnh nhân nhóm thừa cân có vôi hóa động mạch chủ bụng. Vôi hóa động mạch chủ bụng cững gặp nhiều nhất ở nhóm bệnh nhân phát hiện bênh thần trên 5 năm $(32,8 \%)$ và có thời gian loc máu trền 1 năm (56\%). Kết luận: Vôi hóa động mạch chủ bụng là biến đổi thường gặp ở bệnh nhân bệnh thận mạn tính giai đoạn cuối. Chụp CLVT là một kỹ thuật không xâm lấn có thể phát hiện và định lượng chính 
xác vôi hóa mạch máu, giúp các bác sĩ đưa ra các nhận định, tiên lượng và quyết định điều trị.

\section{SUMMARY \\ THE CHARACTERISTICS OF ABDOMINAL AORTIC CALCIFICATION BY NON- CONTRAST COMPUTED TOMOGRAPHY IMAGE IN END-STAGE RENAL DISEASE (ESRD) PATIENTS}

Objectives: Analyzing the characteristics of abdominal aortic calcification (AAC) by non-contrast computed tomography (CT) image in end-stage renal disease (ESRD) patients. Methods: A prospective study was conducted involving 89 ESRD patients who were candidated for kidney transplantation at 103 Military Hospital. The control group consisted of 20 patients without chronic kidney disease (CKD). Noncontrast CT scan was performed to determine the aortic calcification index (ACI) as a semi-quantitative measure of AAC. Results: There were 89 patients (68 males and 21 females), the median age was 36,0 years (Min-max: 18-66 years). AAC was observed in 67 patients (75,3\%) (Median ACI: 4,82\%). Prevalence of AAC had significantly difference between age groups. There were 3 young patients (Younger than 30 years) had $A A C$, and this prevalence in old patients group (Older than 50 years) was $100 \%$. 83,3\% of overweight patients had AAC. AAC was observed most frequently in patients who had detected-kidney disease duration more than 5 years $(32,8 \%)$ and dialysis pre-transplant duration more than 1 year $(56 \%)$. Conclusions: AAC is a common abnormality in ESRD patients. Non-contrast CT is a non-invasive technique for detecting and quantifying vascular calcification, as well as contributing to assessment, prognosis and treatment decision.

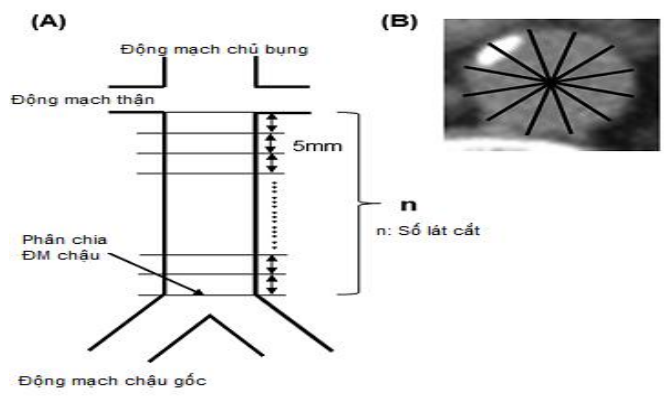

Keywords: Abdominal aortic calcification, endstage renal disease.

\section{I. ĐẶT VẤN ĐỀ}

Vôi hóa mạch máu là một trong những yếu tố nguy cơ của bệnh lý tim mạch ở bệnh nhân bệnh thân mạn tính, làm tăng nguy cơ cao gấp 3-4 lần đối với các biến cố tim mạch và tử vong do tim mạch [1]. Có nhiều phương pháp để xác định vôi hóa mạch máu, trong đó, chụp CLVT không tương phản có thể phát hiện và lượng giá các tổn thương vôi hóa mạch máu.

Bên cạnh việc sàng lọc hẹp lòng động mạch, nhiều nghiên cứu trên thế giới đã khuyến nghị vế tầm quan trọng của việc sàng lọc vôi hóa hệ tim mạch trên những BN BTM.

Chúng tôi thực hiện nghiên cứu với mục tiêu:

Nhận xét đặc điểm vôi hóa động mạch chủ bung bằng chụp CLVT không tương phản ở bệnh nhân bệnh thận mạn tính giai đoạn cuối.

\section{II. ĐỐI TƯợNG VÀ PHƯƠNG PHÁP NGHIÊN CỨU}

89 BN BTM giai đoạn 5 có chỉ định ghép thận tại Bệnh viện Quân y 103, Học viện Quân y từ tháng $9 / 2020$ đến tháng $6 / 2021$. Nhóm chứng gồm 20 BN không có BTM đang điều trị tại Bệnh viện, và có chỉ định chụp CLVT ổ bụng.

Đánh giá AAC trên phim CLVT ổ bụng không có thuốc cản quang, các lát cắt với đồ dày 5 mm. Tổn thương AAC được xác định khi có một vùng $\geq 1 \mathrm{~mm}^{2}$ có hiển thị mật độ $\geq 130$ đơn vị Hounsfield $(\mathrm{HU})$ nằm trên thành động mạch.

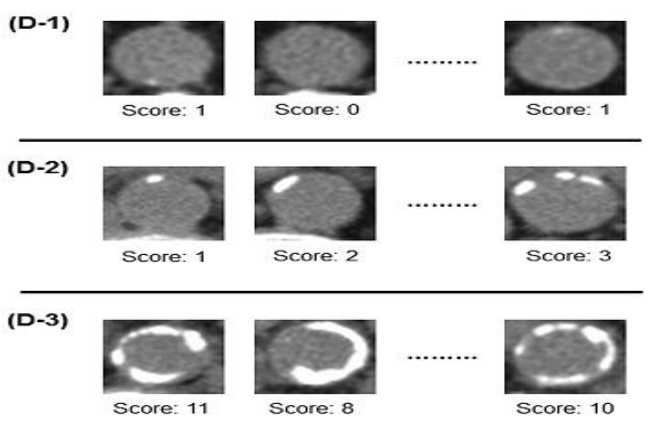

(c)

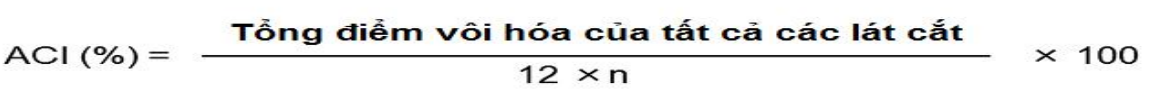

Hình 2.1. Chỉ số vôi hóa động mạch chủ bụng ACI\%

* Nguôn: Theo Tatami và cs (2015) [2]

Điểm ACI được tính cho đoạn động mạch chủ bụng kéo dài từ động mạch thận đến phân nhánh động mạch chậu chung. Các mặt cắt ngang của động mạch chủ bụng trên mỗi lát cắt được chia thành 12 phần bằng nhau, vôi hóa xuất hiện ở mỗi phần được tính là 1 điểm, điểm
$\mathrm{ACI}$ cho mỗi lát cắt động mạch chủ bụng từ 0 đến 12 điểm. Tổng điểm ACI\% của đoạn động mạch chủ bụng được tính bằng tổng điểm $\mathrm{ACI}$ của tất cả lát cắt chia cho tích số lát cắt $(\mathrm{n})$ và 12 [2]. 
III. KẾT QUẢ NGHIÊN CỨU VÀ BÀN LUÂNN 3.1. Đặc điểm chung bệnh nhân nghiên cứu Bảng 3.1. Đặc điểm chung bệnh nhân nghiên cứu $(n=89)$

\begin{tabular}{|c|c|}
\hline $\begin{array}{c}\text { Đắc điếm } \\
\text { bệnh nhân }\end{array}$ & $\begin{array}{c}\text { Mean } \mathbf{\pm} \text { SD/Median } \\
(\text { Min-max } / \mathbf{n}(\%)\end{array}$ \\
\hline Giới tính nam & $68(76,4)$ \\
\hline Tuối $(\mathrm{Năm})$ & $36,0(18-66)$ \\
\hline BMI $\left(\mathrm{Kg} / \mathrm{m}^{2}\right)$ & $20,71 \pm 2,71$ \\
\hline $\begin{array}{c}\text { Thời gian phát hiện } \\
\text { bệnh thận (Tháng) }\end{array}$ & $36,0(1-266)$ \\
\hline $\begin{array}{c}\text { Có lọc máu trước ghép } \\
\text { Thời gian looc máu trước } \\
\text { ghép (Tháng) }\end{array}$ & $70(78,7)$ \\
\hline
\end{tabular}

BMI: Body mass index.

Mean: Giá trị trung bình. SD: Độ lệch chuẩn. Median: Trung vị. n: Số bệnh nhân.

Chúng tôi nghiên cứu trên 89 BN có độ tuổi từ 18 đến 66 (Median: 36,0 tuổi), trong đó, số BN nam chiếm $76,4 \%$, nữ chiếm $23,6 \%$. Tuổi trung bình của $B N$ nghiên cứu phù hợp với nguyên nhân gây suy thận trước ghép phần lớn do viêm cầu thận mạn. Nguyễn Thị Thu Hà và cộng sự (2021) cũng ghi nhận tuổi trung bình BN ghép thận là 36,5 [3]. Thời gian phát hiện bệnh thận trung bình là 36 tháng, tỷ lệ bệnh nhân có điểu trị lọc máu trước ghép là $78,7 \%$ với thời gian lọc máu trung bình là 6 tháng.
3.2. Đặc điểm tổn thương vôi hóa động mạch chủ bụng trên hình ảnh chụp CLVT. Nghiên cứu của chúng tôi tập trung vào phát hiện và định lượng tổn thương vôi hóa trên động mạch chủ bụng. Đây là đoạn động mạch đầu tiên quan sát thấy vôi hóa và mảng xơ vữa, thường xảy ra trước sự phát triển của vôi hóa đông mach vành. Kết quả nhiều nghiên cứu nhận thấy rằng $\mathrm{AAC}$ xuất hiện với tần suất $1 / 3$ ở nhóm người từ 45-54 tuổi, và lên đến $9 / 10$ ở nhóm người trên 75 tuổi. Đối với BN lớn tuổi mắc bệnh đái tháo đường type 2 hoặc BTM cần lọc máu, tỷ lệ hiện mắc nằm trong khoảng từ 84 đến $97 \%$ [4]. Trong các phương pháp khả thi để phát hiện tổn thương vôi hóa mạch máu, chúng tôi lựa chon chụp CLVT ổ bụng không tương phản, là kỹ thuật được chỉ định thường quy và được BHYT chi trả 100\% ở BN tuyển chọn ghép thận.

Bằng phương pháp này, chúng tôi ghi nhận tỷ lệ BN có $A A C$ ( $A C I>0)$ chiếm 75,3\% (Bảng 3.2). Điểm ACI nhỏ nhất là $0 \%$, lớn nhất là $42,13 \%$. Sự khác nhau về tỷ lệ AAC giữa hai nhóm có ý nghĩa thống kê $(p<0,0001)$. ACI\% trung bình ở nhóm nghiên cứu cũng lớn hơn có ý nghĩa thống kê so với ở nhóm chứng, Mean \pm SD lần lượt là $8,59 \pm 10,92$ và $1,4 \pm 4,14 \%$, Median lần lượt là 4,82 và $<0,0001 \%(\mathrm{p}<0,0001)$.

Bảng 3.2. Đặc điểm vôi hóa động mạch chủ bụng trên hình ảnh CLVT

\begin{tabular}{|c|c|c|c|}
\hline Tốn thướng & Nhóm nghiên cứu $(\mathbf{n}=\mathbf{8 9})$ & Nhóm chứng (n= 20) & P \\
\hline Không có vôi hóa, $\mathrm{n}(\%)$ & $22(24,7)$ & $16(80,0)$ & $<0,0001^{\mathrm{a}}$ \\
\hline Có vôii hóa, $\mathrm{n}(\%)$ & $67(75,3)$ & $4(20,0)$ & \\
\hline ACI trung bình (\%) & & & \\
\hline Mean \pm SD & $8,59 \pm 10,92$ & $1,4 \pm 4,14$ & \\
\hline Median (Min - Max) & $4,82(0-42,13)$ & $<0,0001(0-17,31)$ & $<0,0001^{\mathrm{b}}$ \\
\hline
\end{tabular}

ACI: Abdominal Calcification Index.

Mean: Giá trị trung bình. SD: Độ lệch chuẩn. Median: Trung vị. n: Số bệnh nhân.

a: Chi - Square Test. b: Wilcoxon signed-rank Test.

Nhiêu nghiên cứu trong và ngoài nước cũng cho kết quả tương tự (Bảng 3.3):

Bảng 3.3. Tỷ lệ vôi hóa động mạch bụng trong một số nghiên cứu

\begin{tabular}{|c|c|c|c|c|}
\hline Tác giả & Đối tượng nghiên cứu(n) & Nước & Phương pháp & Tỷ lệ AAC (\%) \\
\hline $\begin{array}{l}\text { H. Verma et al. } \\
(2021)[5]\end{array}$ & $\begin{array}{l}\text { BN BTM G4, } 5 \\
(n=150)\end{array}$ & Ấn Độ & $\begin{array}{c}\mathrm{CLV} \sqrt{\mathrm{T}} \\
(\mathrm{ACI} \%)\end{array}$ & 75,3 \\
\hline $\begin{array}{l}\text { K. Furusawa et al. } \\
\text { (2019) [6] }\end{array}$ & $\begin{array}{l}\text { BN BTM chưa lọc máu } \\
(n=218)\end{array}$ & $\begin{array}{l}\text { Nhật } \\
\text { Bản }\end{array}$ & $\begin{array}{l}\mathrm{CLVT} \\
(\mathrm{ACI} \%)\end{array}$ & 89 \\
\hline
\end{tabular}

3.3. Mối liên quan giữa vôi hóa động mach chủ bung trên hình ảnh chụp CLVT và một số thông số. Tuổi là yếu tố nguy cơ tim mạch và mạch máu truyền thống. Tỷ lệ $A A C$ khác nhau có ý nghĩa thống kê giữa các nhóm tuổi $(p<0,0001), 100 \%$ bệnh nhân tuổi trên 50 đều có AAC (Bảng 3.4). $\mathrm{H}$. Verma [5] và $\mathrm{K}$. Furusawa [6] cũng ghi nhận kết quả tương tự.
Đặc biệt, $A A C$ còn xuất hiện ở những $B N$ trẻ tuổi (<30 tuổi), nhưng người thường ít có những yễu tố nguy cơ truyền thống của bệnh lý tim mạch.

AAC xuất hiện nhiều nhất ở nhóm BN có thể trạng trung bình và thừa cân (Lần lượt là 55,2 và $22,4 \%$ ), trong đó, đa số BN thừa cân đều có vôi hóa động mạch (15/18, 83,3\%) (Bảng 3.4). A.D. ter Braake và cộng sự cũng ghi nhận sự khác 
nhau về BMI trung bình giữa 2 nhóm có/không có AAC $(p<0,001)$ [7].

Thời gian phát hiện bênh thận là phản ánh tương đối của thời gian tiến triển bệnh, cũng là thời gian xuất hiện của các rối loạn gây ra bởi BTM. Hiểu theo nghĩa rộng, thời gian phát hiện bệnh thận càng dài sẽ làm tăng nguy cơ $A A C$. Chúng tồi nhận thấy tỷ lệ AAC gặp nhiều nhất ở nhóm $\mathrm{BN}$ phát hiện bệnh thận trên 5 năm $(32,8 \%)$, thấp nhất ở nhóm phát hiện bệnh thận dưới 1 năm $(14,9 \%)$. Sự khác nhau giữa các nhóm có ý nghĩa thống kê ( $p<0,0001)$ (Bảng 3.4).

D.J. Goldsmith và cộng sự nghiên cứu trên BN thận nhân tạo chu kỳ có theo dõi dọc (10-25 năm), kết quả cho thây vôi hóa mạch máu có tỷ lệ $39 \%$ đối với những $\mathrm{BN}$ bắt đâu lọc máu, và $92 \%$ với những $B N$ lọc máu trung bình 16 năm [8]. Kết quả này tương đồng với nghiên cứu của chúng tôi, nhóm $B N$ có thời gian lọc máu trên 1 năm có tỷ lệ $A A C$ cao hơn so với lọc máu dưới 1 năm (56 so với 44\%, $p=0,005$ ) (Bảng 3.4).

Bảng 3.4. Liên quan giữa vôi hóa động mạch chủ bụng với một số thông số

\begin{tabular}{|c|c|c|}
\hline \multirow[b]{2}{*}{ Thông số } & \multicolumn{2}{|c|}{ n (\%) } \\
\hline & $\begin{array}{c}\text { Không vôi } \\
\text { hóa }\end{array}$ & $\begin{array}{c}\text { Có vôi } \\
\text { hóa }\end{array}$ \\
\hline \multicolumn{3}{|c|}{ Nhóm tuối (Năm) } \\
\hline - Dưới 30 tuối & $11(50)$ & $3(4,5)$ \\
\hline$-30-40$ tuối & $10(45,5)$ & $31(46,3)$ \\
\hline$-41-50$ tuối & $1(4,5)$ & $18(26,9)$ \\
\hline - Trên 50 tuối & $0 \mathrm{~m}(0)$ & $15(22,4)$ \\
\hline Tống & $22(100)$ & $67(100)$ \\
\hline $\mathbf{p}$ & \multicolumn{2}{|c|}{$<0,0001$} \\
\hline \multicolumn{3}{|c|}{ BMI $\left(\mathrm{Kg} / \mathbf{m}^{2}\right)$} \\
\hline - Gầy $(<18,5)$ & $7(31,8)$ & $15(22,4)$ \\
\hline - Trung binh $(18,5-22,9)$ & $12(54,5)$ & $37(55,2)$ \\
\hline - Thữa cân $(23-24,9)$ & $3(13,7)$ & $15(22,4)$ \\
\hline - Béo phì $(\geq 25)$ & $0(0)$ & $0(0)$ \\
\hline Tống & $22(100)$ & $67(100)$ \\
\hline $\mathbf{p}$ & \multicolumn{2}{|c|}{0,542} \\
\hline \multicolumn{3}{|c|}{ Thời gian phát hiên bênh thân (Tháng) } \\
\hline$-<12$ tháng & $14(63,6)$ & $10(14,9)$ \\
\hline$-12-36$ tháng & $2(9,2)$ & $19(28,4)$ \\
\hline - $\geq 37-60$ tháng & $3(13,6)$ & $16(23,9)$ \\
\hline - > 60 tháng & $3(13,6)$ & $22(32,8)$ \\
\hline Tống & $22(100)$ & $67(100)$ \\
\hline $\mathbf{p}$ & \multicolumn{2}{|c|}{$<0,0001$} \\
\hline \multicolumn{3}{|c|}{ Thời gian lọc máu trước ghép (Tháng) } \\
\hline$-<12$ tháng & $18(90,0)$ & $22(44,0)$ \\
\hline - 12-36 tháng & $2(10,0)$ & $18(36,0)$ \\
\hline - $\geq 37-60$ tháng & $0(0)$ & $5(10,0)$ \\
\hline - > 60 tháng & $0(0)$ & $5(10,0)$ \\
\hline Tống & $20(100)$ & $50(100)$ \\
\hline 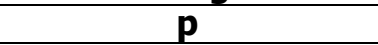 & \multicolumn{2}{|c|}{0,005} \\
\hline
\end{tabular}

p: Pearson Chi - Square Test.

\section{KẾT LUÂ̂N}

Nghiên cứu đặc điểm vôi hóa động mạch chủ bụng bằng chụp CLVT không tương phản ở 89 BN ESRD, chúng tôi rút ra một số kết luận sau:

- Vôi hóa động mạch chủ bụng là biến đổi thường gặp ở BN BTM có hoặc không có lọc máu chu kỳ, tỳ lệ BN có $A A C$ là 75,3\%; tỷ lệ vôi hóa mức đố nặng là $23,9 \%$. Tỷ lệ $A A C$ và điểm vôi hóa trung bình khác nhau có ý nghĩa thống kê giữa nhóm nghiên cứu và nhóm chứng $(p<0,05)$.

- Tỷ lệ AAC khác nhau có ý nghĩa thống kê giữa các nhóm tuổi, thời gian phát hiện bệnh thận và thời gian lọc máu trước ghép, cao nhất ở nhóm BN trên 50 tuổi, có BMI cao, thời gian phát hiện bệnh trên 5 năm, thời gian lọc máu trên 1 năm.

\section{TÀI LIÊU THAM KHẢO}

1. Rennenberg R., Kessels A., Schurgers $L_{\text {, }}$ et al. (2009), "Vascular calcifications as a marker of increased cardiovascular risk: A meta-analysis", Vascular Health and Risk Management 5(1), 185-197.

2. Tatami Y., Yasuda Y., Suzuki S., et al. (2015), "Impact of abdominal aortic calcification on long-term cardiovascular outcomes in patients with chronic kidney disease", Atherosclerosis, 243(2), 349-355.

3. Nguyễn Thị Thu Hà, Bùi Văn Mạnh, Nguyễn Thị Thùy Dung, et al. (2021), "Long Hemodialysis Duration Predicts Delayed Graft Function in Renal Transplant Recipients From Living Donor: A Single-Center Study", Transplantation Proceedings, 53(5), 1477-1483.

4. Leow K., Szulc $P_{.,}$Schousboe J. T., et al. (2021), "Prognostic value of abdominal aortic calcification: a systematic review and meta-analysis of observational studies", Journal of the American Heart Association, 10(2), e017205.

5. Verma H., Sunder S., Sharma B., et al. (2021) "Prevalence of Vascular Calcification in Chronic Kidney Disease Stage 4 and 5 Patients and its Correlation with Inflammatory Markers of Atherosclerosis", Journal of Kidney Diseases Transplantation, 32(1), 30.

6. Furusawa K., Takeshita K., Suzuki S., et al. (2019), "Assessment of abdominal aortic calcification by computed tomography for prediction of latent left ventricular stiffness and future cardiovascular risk in pre-dialysis patients with chronic kidney disease: A single center cross-sectional study", International journal of medical sciences, 16(7), 939.

7. Ter Braake A. D., Govers L. P., Peeters M. J., et al. (2021), "Low plasma magnesium concentration and future abdominal aortic calcifications in moderate chronic kidney disease", BMC Nephrology, 22(1), 1-10.

8. Goldsmith D. J., Covic A., Sambrook P. A., et al. (1997), "Vascular calcification in long-term haemodialysis patients in a single unit: A retrospective analysis", Nephron, 77(1), 37-43. 